\title{
A CLINICAL STUDY OF EVALUATION AND MANAGEMENT OF BLUNT TRAUMA ABDOMEN
}

\author{
Saptagiri R. Prasad ${ }^{1}$, N. Lingaraju ${ }^{2}$ \\ ${ }^{1}$ Civil Assistant Surgeon. \\ ${ }^{2}$ Associate Professor, Department of Surgery, MIMS, Mandya.
}

\begin{abstract}
Blunt abdominal trauma is a leading cause of morbidity and mortality among all age groups. Usually results from Motor Vehicle Collisions (MVCs), assaults, recreational accidents or falls. The most commonly injured organs are the spleen, liver, retroperitoneum, small bowel, kidneys, bladder, colorectum, diaphragm and pancreas. Identification of serious intra-abdominal pathology is often challenging. Missed intra-abdominal injuries and concealed haemorrhage are frequent causes of increased morbidity and mortality, especially in patients who survive the initial phase after an injury.
\end{abstract}

\section{AIM}

To find out age and sex incidence of blunt trauma abdomen and to evaluate available investigations for early diagnosis, various modalities of treatment and their outcome.

\section{MATERIALS AND METHODS}

Prospective interventional study of 50 patients over two-year period. All the patients presenting to the emergency room in PESIMSR with blunt injury abdomen were included in the study.

\section{RESULTS}

Males were predominantly affected ratio being 4:1 in the age group of 21-40 years. Out of 50 patients, 25 (50\%) were managed conservatively and 25 were managed by operative methods. Of them 45 were cured and discharged, 3 expired, 2 were referred to higher centres for further management. Spleen was the commonest visceral organ injured in our study accounting for $50 \%$ of total cases followed by liver, which was found in $22 \%$ of cases. USG abdomen was found to be the most useful initial investigative modality; post-operative complications were seen in about 11 patients; average hospital stay was about 10 days. Conservative management was equally successful as operative management in carefully selected patients.

\section{CONCLUSION}

The most common cause of abdominal injury was road traffic accident with solid organ injuries being more. USG was found to be the most useful investigation for early diagnosis and majority were managed conservatively with good results. Early transportation of the patients to the hospitals with better resuscitation at the scene of accident and on arrival early diagnosis and early surgery and better postoperative care of the patient have totally changed the mortality and morbidity to a minimum with more patients going from the hospital successfully and earlier.

\section{KEYWORDS}

Blunt Injury, Splenectomy, Splenorrhaphy, Hepatorrhaphy, USG, Postoperative Care.

HOW TO CITE THIS ARTICLE: Prasad SR, Lingaraju N. A clinical study of evaluation and management of blunt trauma abdomen. J. Evolution Med. Dent. Sci. 2016;5(29):1492-1496, DOI: 10.14260/jemds/2016/351

\section{INTRODUCTION}

As the world-wide population is increasing, there is an increase in incidence of road traffic accidents and violent trauma. India has one of the highest accident rates in the world. Civilian trauma remains the fourth leading cause of death in U.S. In India more than $70 \%$ of our population dwells in villages where very few trauma care centres are available. Thus, the care of abdominal injury patients is far from satisfactory. As abdominal injuries are mainly seen in young and economically productive individuals, we need to develop effective trauma care and save many innocent lives.

Financial or Other, Competing Interest: None.

Submission 04-03-2016, Peer Review 18-03-2016,

Acceptance 22-03-2016, Published 11-04-2016.

Corresponding Author:

Dr. Saptagiri R. Prasad,

Door No. 4/81, Upstairs,

Kalahastam Street, Venkatagiri Peta,

Proddatur Kadapa-516360

Andhra Pradesh.

E-mail: saptagiriprasad@gmail.com

DOI: $10.14260 /$ jemds $/ 2016 / 351$
More than half of these trauma-related deaths are the result of motor vehicle accidents. Other common causes include falls, gunshot or stab wounds, poisoning, burns and drowning. Abdomino-pelvic trauma accounts for a large fraction of this tragic loss of life and continues to be a distressingly frequent cause of preventable death. Peritoneal signs in these patients can be subtle and frequently unreliable, secondary to distracting pain from associated injuries or decreased sensorium owing to intoxicants or head injury.

Favourable outcome of these critically injured patients demands an integrated multi-disciplinary team effort beginning at the injury of scene and continuing through rehabilitation. Initial management is dictated by patient's immediate physiologic requirements for survival (i.e. ABCsairway, breathing, circulation) and is often initiated before the establishment of specific diagnosis. Multiple lifethreatening injuries often coexist, requiring rapid triage with simultaneous diagnostic and therapeutic interventions. The trauma surgeon must assume ultimate responsibility for the injured patient, assimilating key diagnostic results and 
orchestrating specific management, implemented by trauma team members.

\section{MATERIAL AND METHODS}

It was a prospective interventional study done in the Department of Surgery, PESIMSR, Kuppam, a tertiary care centre from 2010 to 2012 . All the patients presenting to the emergency room with blunt injury abdomen are included in the study. After initial triage, resuscitation of the patient was done According to the haemodynamic status of the patient blood/blood components administered. Data collected and a detailed clinical examination with documentation was done. All the baseline investigations and specific investigations were performed. Imaging investigations like plain X-ray abdomen, U/S abdomen and CT abdomen (In selective cases) were done. Based on the analysis of data, a decision regarding conservative management or emergency surgical management was taken.

\section{RESULTS}

A detailed study of 50 patients who are admitted to emergency room with blunt injury abdomen was done. The analysis is based on the age, sex, viscera injured, methods of evaluation and management in these patients.

Table 1 shows majority of these patients were found in the age group of 21-40 years, which is a period of productive physical activity. Males outnumbered females, the ratio being $4: 1$ that is 10 out of 50 patients.

\begin{tabular}{|c|c|c|c|c|}
\hline $\begin{array}{c}\text { Age } \\
\text { Group }\end{array}$ & Male & Female & $\begin{array}{c}\text { No. of } \\
\text { Patients }\end{array}$ & Percentage \\
\hline $0-10$ years & 1 & 1 & 2 & 4.00 \\
\hline $\begin{array}{c}11-20 \\
\text { years }\end{array}$ & 7 & 0 & 7 & 14.00 \\
\hline $\begin{array}{c}21-30 \\
\text { years }\end{array}$ & 9 & 4 & 13 & 26.00 \\
\hline $\begin{array}{c}31-40 \\
\text { years }\end{array}$ & 16 & 3 & 19 & 38.00 \\
\hline $\begin{array}{c}41-50 \\
\text { years }\end{array}$ & 6 & 2 & 8 & 16.00 \\
\hline$>50$ years & 1 & 0 & 1 & 2.00 \\
\hline Total & $\mathbf{4 0}$ & $\mathbf{1 0}$ & $\mathbf{5 0}$ & $\mathbf{1 0 0 . 0 0}$ \\
\hline \multicolumn{5}{|c|}{ Table 1: Age and Sex Incidence } \\
\hline
\end{tabular}

Table 2 shows results of plain X-ray done in 39 of 50 patients. In 11 patients, it was not done because the patient's condition did not permit to shift them to the X-ray room. Among them Gas under the diaphragm was found in $6(12 \%)$, Ground glass appearance in 8 (16\%), Fracture of ribs in 5 (10) cases.

\begin{tabular}{|c|c|c|}
\hline Feature & $\begin{array}{c}\text { No. of } \\
\text { Patients }\end{array}$ & Percentage \\
\hline Gas under diaphragm & 6 & 12 \\
\hline Ground glass appearance & 8 & 16 \\
\hline $\begin{array}{c}\text { Enlarged soft tissue shadow (Peri- } \\
\text { hepatic/perisplenic/obliteration } \\
\text { of psoas shadow }\end{array}$ & 9 & 18 \\
\hline $\begin{array}{c}\text { Fracture of ribs } \\
\text { Herniation of stomach through } \\
\text { diaphragm }\end{array}$ & 1 & 10 \\
\hline No radiological abnormality & 10 & 20 \\
\hline Not done & 11 & 22 \\
\hline \multicolumn{2}{|c|}{ Table 2 } \\
\hline
\end{tabular}

Table 3 shows results of ultrasound abdomen definite solid organ injuries with free fluid in 29 (58\%) cases, free fluid in $6(12 \%)$ and equivocal in $15(30 \%)$ cases. These 15 patients with suspicious and equivocal signs were subjected for CT abdomen.

\begin{tabular}{|c|c|c|}
\hline Findings & $\begin{array}{c}\text { Number of } \\
\text { Cases }\end{array}$ & Percentage \\
\hline $\begin{array}{c}\text { Solid organ injuries with } \\
\text { free fluid }\end{array}$ & 29 & 58 \\
\hline Free fluid & 6 & 12 \\
\hline Suspicious and equivocal & 15 & 30 \\
\hline \multicolumn{2}{|c|}{ Table 3 } \\
\hline
\end{tabular}

Table 4 shows findings of CT scan in 15 patients, who had the equivocal or suspicious findings on USG.

\begin{tabular}{|c|c|c|}
\hline $\begin{array}{c}\text { Sl. } \\
\text { No. }\end{array}$ & Organ Injured & $\begin{array}{c}\text { Number of } \\
\text { Cases }\end{array}$ \\
\hline 1 & Liver contusion & 2 \\
\hline 2 & Liver laceration & 1 \\
\hline 3 & Splenic laceration & 4 \\
\hline 4 & Splenic contusion & 2 \\
\hline 5 & $\begin{array}{c}\text { Both splenic laceration and liver } \\
\text { laceration }\end{array}$ & 1 \\
\hline 6 & Contusion of pancreas & 1 \\
\hline 7 & Retroperitoneal haematoma & 2 \\
\hline 8 & Renal laceration & 1 \\
\hline 9 & Diaphragmatic hernia & 1 \\
\hline \multicolumn{2}{|c|}{ Table 4 } \\
\hline
\end{tabular}

Table 5 shows relative incidence of various injured organs, among which Spleen (Fig. 1) was the commonest visceral organ accounting for $50 \%$ of total cases followed by liver (Fig. 2 ), which was found in $22 \%$ of cases.

\begin{tabular}{|c|c|c|}
\hline & No. of Cases & $\%$ \\
\hline Spleen & 25 & $50 \%$ \\
\hline Small bowel & 06 & $12 \%$ \\
\hline Liver & 11 & $22 \%$ \\
\hline Retroperitoneal haematoma & 2 & $4 \%$ \\
\hline Rectum & 1 & $2 \%$ \\
\hline Mesentery & 1 & $2 \%$ \\
\hline Kidney & 1 & $2 \%$ \\
\hline Pancreas & 1 & $2 \%$ \\
\hline Diaphragm with rupture uterus & 1 & $2 \%$ \\
\hline Both liver and spleen & 1 & $2 \%$ \\
\hline
\end{tabular}

\begin{tabular}{|c|c|c|c|c|c|c|}
\hline Organ & \multicolumn{2}{|c|}{ Spleen } & \multicolumn{2}{c|}{ Liver } & Small Bowel \\
\hline Sl. No. & $\begin{array}{c}\text { Grade } \\
\text { of } \\
\text { Injury }\end{array}$ & $\begin{array}{c}\text { No. of } \\
\text { Cases }\end{array}$ & $\begin{array}{c}\text { Grade } \\
\text { of } \\
\text { Injury }\end{array}$ & $\begin{array}{c}\text { No. of } \\
\text { Cases }\end{array}$ & $\begin{array}{c}\text { Grade } \\
\text { of } \\
\text { Injury }\end{array}$ & $\begin{array}{c}\text { No. of } \\
\text { Cases }\end{array}$ \\
\hline 1 & I & 3 & I & 4 & I & 0 \\
\hline 2 & II & 9 & II & 6 & II & 5 \\
\hline 3 & III & 7 & III & 1 & III & 1 \\
\hline 4 & IV & 6 & IV & 0 & IV & 0 \\
\hline 5 & V & 0 & V & 0 & V & 0 \\
\hline \multicolumn{7}{|c|}{} \\
\hline \multicolumn{7}{|c|}{ Table 6: Shows Grades of Injuries of Different } \\
Organs Involved in Blunt Injury Abdomen \\
\hline Organ
\end{tabular}




\begin{tabular}{|c|c|c|}
\hline Injured & Procedure & Patients \\
\hline Spleen & $\begin{array}{c}\text { Splenectomy } \\
\text { Splenorrhaphy }\end{array}$ & 10 \\
\hline Liver & $\begin{array}{c}\text { Hepatorrhaphy } \\
\text { Haemostasis and } \\
\text { drainage }\end{array}$ & 2 \\
\hline Small bowel & $\begin{array}{c}\text { Primary closure } \\
\text { Perforation } \\
\text { Resection and end-to- } \\
\text { end anastomosis }\end{array}$ & 1 \\
\hline Rectum & Hartmann's procedure & 1 \\
\hline \multicolumn{2}{|c|}{$\begin{array}{c}\text { Closure of tear with } \\
\text { resection of bowel and } \\
\text { end-to-end anastomosis }\end{array}$} & 1 \\
\hline Mesentery & $\begin{array}{c}\text { Hysterectomy } \\
\text { hernia with } \\
\text { ruptured uterus }\end{array}$ & 1 \\
\hline \multicolumn{2}{|c|}{ Nonoperative Management } \\
\hline Table 7: Shows type of Management and Operative \\
Procedure done in Blunt Injury Abdomen Patients \\
\hline
\end{tabular}

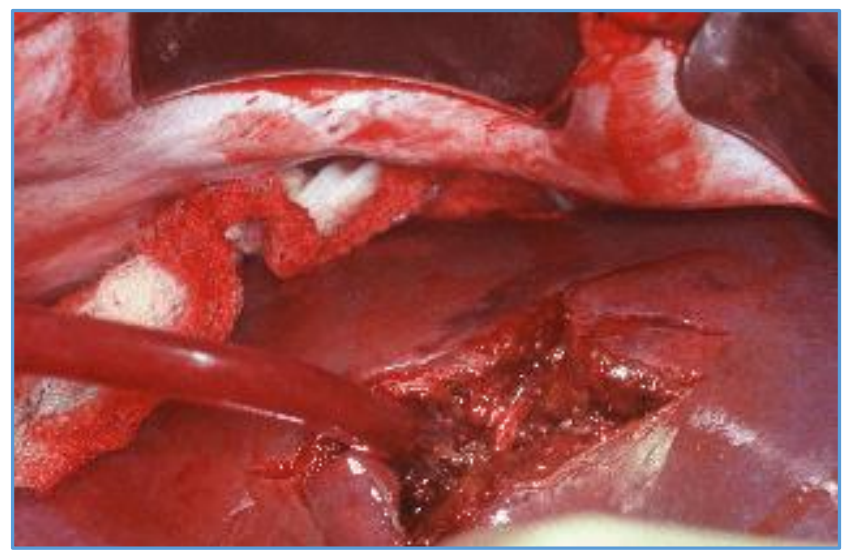

Fig. 2: Liver Laceration

Out of 50 patients 45 were cured and discharged, 3 expired, 2 were referred to higher centres for further management.

The 3 cases which were expired had rectal prolapsed in one patient with liver laceration and one with splenic laceration.

The mortality in the present study was $6 \%$, i.e. 3 out of 50 patients were expired.

A case of rectal prolapse was expired due to sepsis and the other two one with liver laceration and another with splenic laceration due to irreversible hypovolemic shock.

The 2 cases which were referred are one with renal laceration and one with diaphragmatic hernia for urological and cardiothoracic management respectively.

Table 8 shows post-operative complications among patients who had operative management.

\begin{tabular}{|c|c|}
\hline Post-Operative Complications & No. of Patients \\
\hline Bronchopneumonia & 4 \\
\hline Prolonged ileus & 5 \\
\hline Wound infection & 2 \\
\hline Table 8: Post-Operative Complications \\
\hline
\end{tabular}

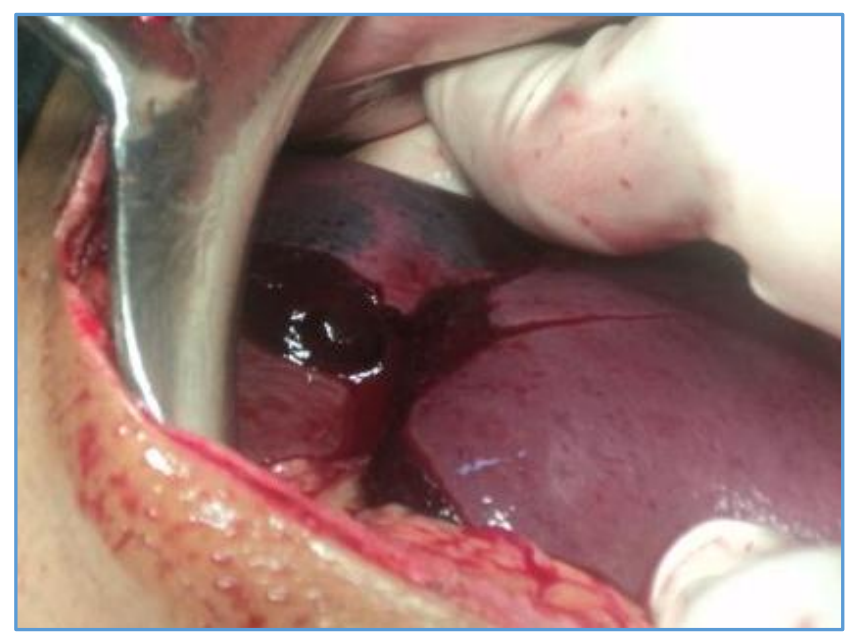

Fig. 1: Splenic Laceration

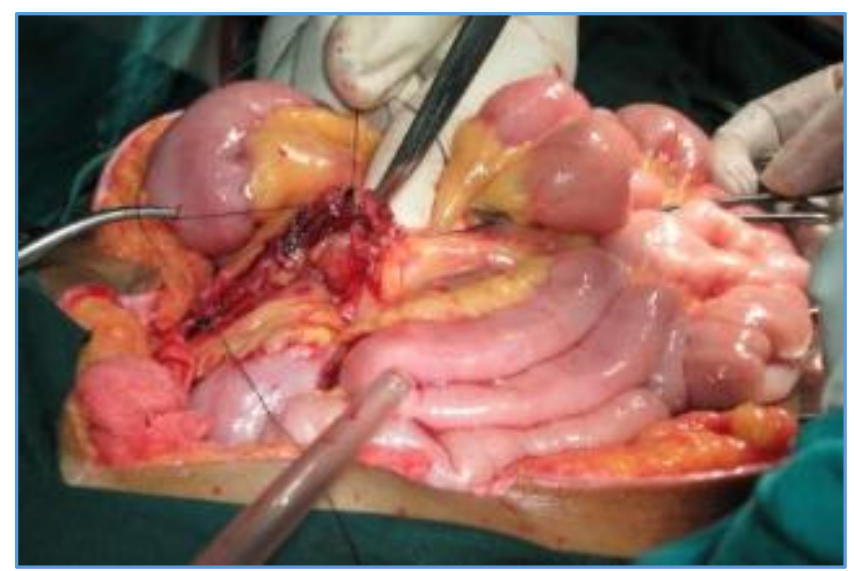

Fig. 3: Mesenteric Tear

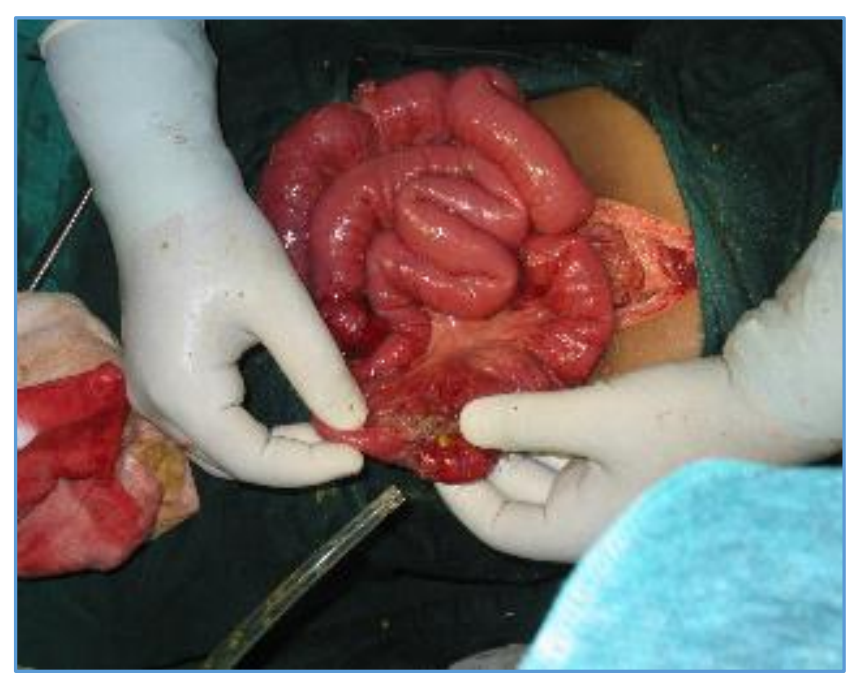

Fig. 4: Partial Transection of Small Bowel

\section{DISCUSSION}

The abdomen is a diagnostic black box. It is most commonly involved following blunt trauma. ${ }^{1}$ Injury has been man's constant companion since earliest times.

Modern trauma care has been increasing in sophistication all the time. However, despite its huge importance blunt trauma has been called the neglected disease of modern society. ${ }^{2}$ The trauma can be either from road traffic accidents, accidental fall from height, sports injury or violence. Motor vehicle accidents account for 75$80 \%$ of blunt trauma of abdomen. ${ }^{3}$ 
Blunt abdominal trauma is a leading cause of morbidity and mortality among all age groups. Identification of serious intra-abdominal pathology is often challenging. Many injuries may not manifest during the initial assessment and treatment period. Missed intra-abdominal injuries and concealed haemorrhage are frequent causes of increased morbidity and mortality, especially in patients who survive the initial phase after an injury.

Physical examination findings are notoriously unreliable. One reason is that mechanisms of injury often result in other associated injuries that may divert the physician's attention from potentially life-threatening intraabdominal pathology. Other common reasons are an altered mental state and drug and alcohol intoxication.

Coordinating a trauma resuscitation demands a thorough understanding of the pathophysiology of trauma and shock, excellent clinical and diagnostic acumen, skill with complex procedures, compassion and the ability to think rationally in a chaotic milieu.

In blunt trauma, more energy is transferred over a wider area than from a Gunshot Wound (GSW) or Stab Wound (SW). As a result, blunt trauma is associated with multiple widely distributed injuries. Trauma surgeons often separate patients who have sustained blunt trauma into categories according to their risk for multiple injuries. a) High Energy Transfer - include auto-pedestrian accidents, motor vehicle accidents in which change of speed of car exceeds 20 mph or in which the patient has been ejected, motor cycle accidents and falls from heights greater than 20 feet. b) Low Energy Transfer - such as struck with a club or falling from a bicycle.

Initial evaluation and resuscitation should simultaneously occur which begins at the scene of the injury with information provided by the patient, family, bystanders or paramedics.

\section{Key Elements of the Pertinent History include the following: \\ AMPLE \\ - Allergies. \\ - Medications. \\ - Past Medical History. \\ - Last meal or other oral intake. \\ - Events leading to presentation.}

Assessment of haemodynamic stability is most important initial concern in the evaluation of patient with blunt abdominal injury. In the haemodynamically unstable patient, a rapid evaluation of haemoperitoneum can be accomplished by means of diagnostic peritoneal lavage or the Focused Assessment with Sonography for Trauma (FAST).

Radiographic studies of the abdomen are indicated in stable patient when physical examination are inconclusive. Plain abdominal radiograph in erect position is helpful in hollow visceral injury. Hollow visceral injury shows free air doom of diaphragm. This was seen in 6 patients of the study. Davis et al. ${ }^{4}$ reported that in their series, abdominal X-ray was abnormal in $21 \%$ of cases; pneumoperitoneum was detected in $6 \%$ of cases and dilated bowel loops in $6 \%$ of cases.

USG on the other hand is safer, simpler to perform, relatively cost effective and rapid to find significant haemoperitoneum and simultaneously evaluate the thorax, pleural collection and retroperitoneum in addition to abdomen and helpful in unstable patient. Boulanger et al. ${ }^{5}$ in 1999 revealed that USG based algorithm for blunt abdominal trauma was more rapid, less expensive and the USG machine being portable. In present study all 50 patients were subjected for ultrasound examination, out of which 29 patients had solid organ injuries with haemoperitoneum or free fluid.

The current FAST examination protocol consists 4 acoustic window (Peri-cardiac, peri-hepatic, peri-splenic and pelvic) with the patient in supine. An examination is interpreted as positive if free fluid is found in any of the 4 acoustic windows, negative if no fluid is seen and indeterminate if any of the windows cannot be adequately assessed.

FAST can be completed in 3 to 4 minutes. The minimum threshold for detecting haemoperitoneum is unknown, but remains a subject of interest. Kawaguchi and Colleagues found that $70 \mathrm{~mL}$ of blood could be detected. ${ }^{5}$ whereas Tiling et al. ${ }^{4}$ found that $30 \mathrm{~mL}$ is the minimum requirement for detecting with ultrasonography. ${ }^{6}$ Generally, FAST diagnostic accuracy is equal to that of DPL sensitivity and specificity of these fast ranges from $85 \%$ to $90 \% .5,6,7,8$

Computed tomography is the standard for detecting solid organ injuries. CT can provide excellent imaging of pancreas, duodenum and genitourinary system. CT scanning often provides the most detailed images of traumatic pathology and may assist in determination of operative intervention. ${ }^{9,10,11}$ Unlike DPL or FAST, CT can determine the source of haemorrhage.

The incidence of various organs injured were found like majority were splenic injuries accounting for 50\% cases, which is comparable with COX et al. ${ }^{12}$ study followed by injuries to liver $22 \%$, which was also similar in two more studies Cusheri et al. and Davis et al. ${ }^{4}$ study. Least being injuries to Rectum, Mesentery (Fig. 3), Kidney, Pancreas.

Majority of the splenic injuries, liver injuries, small bowel (Fig. 4) were found as Grade II that is 36\%, 54\% and $83.3 \%$ respectively.

The most common operative procedure performed in present study was splenectomy that is in 10 patients among 25 patients of surgically managed constituting $40 \%$, followed by closure of bowel perforation that is $24 \%$.

In Khanna et al. study closure of bowel perforation was done in 13 patients, colostomy in 2 patients, repair of mesentery in 9 patients, splenectomy in 4 patients, splenorrhaphy in 1 patient and hepatorrhaphy in 6 patients; $50 \%$ of patients were managed conservatively, other $50 \%$ by operative methods; so compared to other studies the operative management was increased. Davis et al. showed $77 \%$ and Khanna et al. ${ }^{13}$ showed that $58 \%$ of patients were subjected for conservative management.

The post-operative complications were found among $22 \%$ of patients, major being bronchopneumonia contributing to $45 \%$.

Out of 50 patients 45 were cured and discharged, 3 expired, 2 were referred to higher centres for further management. Study by Davis et al. showed 15\% mortality with septicaemia, the most common cause of death.

\section{CONCLUSION}

Blunt abdominal trauma is one of the commonest cause of morbidity and mortality among all age groups in modern era 
Identification of serious intra-abdominal pathology is often challenging. A thorough and repeated examination and appropriate diagnostic investigations leads to successful treatment in these cases. Plain erect X-ray abdomen is a valuable investigation taken for gastrointestinal injuries. Spleen is the most commonly injured organ and majority of them were managed conservatively. With better resuscitation at the scene of accident, early transportation of the patients to the hospitals, early diagnosis and early surgery and better postoperative care of the patient have totally changed the mortality and morbidity to a minimum with more patients are going from the hospital successfully and earlier. In the present study, we conclude that non-operative management is equally effective compared to operative management in patients with blunt abdominal injury.

\section{REFERENCES}

1. Hamilton bailey 's emergency surgery, CRC Press $13^{\text {th }}$ edition:446-471.

2. Cusheri A Giles G R Moosa A R Essential surgical practice 1998. p 263-304.

3. Michael J. Zinner, Stanley w ashly Maingot 's abdominal operations $11^{\text {th }}$ edition $\mathrm{p}$ 772-784.

4. Joe Jack Davis, Isidore Cohn, Francis C Nance. Diagnosis and management of blunt abdominal trauma. Ann Surg 1976;183(6):672-8.

5. Boulanger BR, Mcellan BA, Brenneman FD, et al. Prospective evidence of the susperiority of a sonography based algorithm in the assessment of blunt abdominal injury. J Trauma 1999;47(4):632-7.
6. Kawaguchi S, Toyonaga J, Lkeda K. Five point method: an ultrasonographic quantification formula of intra abdominal fluid collection. Jpn J Acute Med 1987;7:9937.

7. Tiling T, Boulion B, Sochid A, et al. Ultrasound in blunt abdomino-thoracic trauma in: Border JR, ed. Blunt multiple trauma. Comprehensive patho-physiology and care. New York Marcel Dekker. 1990;415-33.

8. Jolly S, Upadyay M, Jain BL. Blunt injury abdomen-a review. J Trauma 2010;69(2):302-7.

9. Brasel KJ, Olson CJ, Stafford RE, et al. Incidence and sighificance of free fluid on abdominal computed tomographic scan in blunt trauma. J Trauma 1998;44(5);889-92.

10. Christiano JG, Tummers M, Kennedy A. Clinical significance of isolated intraperitoneal fluid on computed tomography in pediatric blunt abdominal trauma. J Pediatr Surg 2009;44(6):1242-8.

11. Musami Singh, Amit Kumar, Verma AK, et al. Abdominal organ involvement in blunt injuries. J indian Acad Forensic medicine 2012;34(1):24-26.

12. Cox EF. Blunt abdominal trauma: a 5 year analysis of 870 patients requiring celiotomy. Ann Surg 1984;199(4):467-74.

13. Khanna R, Khanna S, Singh $P$, et al. Spectrum of blunt abdominal trauma in Varanasi. Quart J 1999;35(1\&2):25-8. 